\title{
What to do with a clinical trial with conflicts of interest
}

\section{Andreas Lundh, ${ }^{\oplus, 2,3,4}$ Isabelle Boutron, ${ }^{5,6,7}$ Lesley Stewart, ${ }^{8}$ Asbjorn Hróbjartsson ${ }^{1,2,3}$}

10.1136/bmjebm-2019-111230

${ }^{1}$ Centre for Evidence-Based

Medicine Odense (CEBMO),

Odense University Hospital,

Odense, Denmark

${ }^{2}$ Open Patient data

Exploratory Network (OPEN),

Odense University Hospital,

Odense, Denmark

${ }^{3}$ Department of Clinical

Research, University of

Southern Denmark, Odense,

Denmark

${ }^{4}$ Department of Infectious

Diseases, Hvidovre Hospital,

Hvidovre, Denmark

${ }^{5}$ Equipe METHODS, Centre

de Recherche Épidémiologie

et Statistique Sorbonne

Paris Cité (CRESS-UMR1153)

Inserm, Paris, France

${ }^{6}$ Université Paris Descartes,

Paris, France

${ }^{7}$ Cochrane France, Paris,

France

${ }^{8}$ Centre for Reviews and Dissemination, University of

York, York, UK

Correspondence to: Dr Andreas Lundh, Centre for Evidence-Based Medicine Odense (CEBMO), Odense University Hospital, 5000 Odense C, Denmark; andreas. hover.lundh@rsyd.dk

\section{Check for updates}

(- Author(s) (or their employer(s)) 2018. No commercial re-use. See rights and permissions. Published by BMJ.

To cite: Lundh A, Boutron I, Stewart L, et al. BMJ

Evidence-Based Medicine

Epub ahead of print:

[please include Day Month

Year]. doi:10.1136/

bmjebm-2019-111230
Financial considerations, personal conviction and concerns about academic careers may influence how research is designed, conducted and reported. ${ }^{1}$ This has recently been highlighted in the case of harms from transvaginal mesh devices and cases of research misconduct where pressure to ensure funding and academic prestige have compromised science. ${ }^{2-4}$ Less dramatic examples are the overinterpretation of study findings or downplaying of harms. ${ }^{56}$ Such practices may be caused by conflicts of interest which can be defined as circumstances that create a risk that professional judgement or actions regarding a primary interest will be unduly influenced by a secondary interest. ${ }^{1}$

Concern for conflicts of interest are particularly important in clinical trials, as trials play a central role in clinical practice, by providing the basis for regulatory drug and device approval and by producing evidence to guide clinical decision-making and clinical guideline recommendations. ${ }^{1}$ About $40 \%$ of clinical trials and $70 \%$ of drug trials are commercially funded, and a similar proportion of drug trials have authors with industry ties, though there is large variation across medical specialties. ${ }^{78}$ Both industry funding and investigator ties are associated with more favourable trial outcomes ${ }^{89}$ and cases revealing 'spin' and reporting biases in industry trials have been described. ${ }^{10}$

There is wide debate about how associations between financial conflicts of interest and favourable trial outcomes should be interpreted. ${ }^{911}$ Some have argued that there is more pronounced bias in the estimated treatment effects generated by trials with conflicts of interest, while others have argued that this association may be explained by underlying differences in the type of hypotheses tested and the design used in such trials compared with independent trials, for example, differences in choice of participants, comparators or outcomes. ${ }^{9}$

In addition, independent academic trials that are free from commercial influence are not necessarily problem free. Investigators may have other non-financial conflicts of interest, for example, strong specialty interests or personal beliefs ${ }^{12}$ and this may shape how trials are designed, analysed or reported. Accordingly, disclosure of both financial and non-financial conflicts of interest is considered important by journals ${ }^{13}$ and trials with disclosed conflicts are generally perceived as being less reliable by journal readers. ${ }^{14}$

It is currently unclear how disclosed conflicts of interest should be most appropriately interpreted when appraising trial reports-either as reader of a journal article or in the context of conducting a systematic review. Roseman and colleagues found that only 2 of 29 non-Cochrane systematic reviews of drug trials reported trial funding sources, and none of the reviews included information on trial authors' conflicts of interest. ${ }^{15}$ Another study reported that around $30 \%$ of Cochrane reviews incorporated trial funding or author conflicts of interest directly in the risk of bias assessment. ${ }^{16}$ However, the Cochrane Handbook discourages this practice as any bias from conflicts of interest should already be captured by the domains included in the Cochrane Risk of Bias Tool (eg, selective reporting). ${ }^{16}$ Nevertheless, there is currently little practical guidance for how to tackle conflicts of interest and there is therefore a clear need for a broader consensus on how information on trial funding and authors' conflicts of interest should be addressed in systematic reviews.

In 2015, members of the Cochrane Bias Methods Group, responsible for updating the Cochrane risk of bias tool, agreed that further guidance was needed and assembled a group to develop this. The group includes researchers with experience in trial and systematic review methodology, industry involvement, journal editors, as well as experts in conflicts of interest research. The aim is to develop a Tool for Addressing Conflicts of Interest in Trials (TACIT) to help systematic review authors address the potential influence of conflicts of interest in their review.

TACIT facilitates gathering and processing information about conflicts of interest which may be used to: (1) conduct risk of bias assessment of an individual trial; (2) assess risk of bias due to missing results in a meta-analysis; (3) as a guide for secondary meta-analyses (subgroup or sensitivity analyses) and (4) inform reflections on variability and applicability of meta-analytical result. ${ }^{11}$ TACIT development is underpinned by a systematic review of how critical appraisal tools address conflicts of interest and by a survey and qualitative interview study of experienced trialists. TACIT is planned to be pilot tested by expected end users. The framework of TACIT is also included in the chapter on bias and conflicts of interest in the upcoming version of the Cochrane Handbook. ${ }^{17}$ Updates on tool development can be found on the TACIT website (www.tacit.one) and the tool is expected to be released in 2020. The tool is intended primarily for systematic review authors but may also be 
useful for peer reviewers, editors, guideline authors or other readers of trial reports.

Contributors AL drafted the manuscript and all authors were involved in writing of the manuscript and approved the final version of the manuscript. AL is the guarantor and accepts full responsibility of the work. All authors were involved in the decision to publish.

Competing interests All authors are members of the TACIT steering group. We declare that we have no other competing interests.

\section{Patient consent for publication Not required.}

Provenance and peer review Not commissioned; externally peer reviewed.

\section{References}

1. IOM (Institute of Medicine). Conflict of interest in medical research, education, and practice. Washington, DC: The National Academies Press, 2009.

2. Heneghan C, Godlee F. Surgical mesh and patient safety. BMJ 2018;363:k4231.

3. Shuchman M. Stopping the slide to research fraud. CMAJ 2017;189:E256-7.

4. Kupferschmidt K. Researcher at the center of an epic fraud remains an enigma to those who exposed him. Science 2018:1-45.

5. Boutron I, Dutton S, Ravaud P, et al. Reporting and interpretation of randomized controlled trials with statistically nonsignificant results for primary outcomes. JAMA 2010;303:2058-64.

6. Wang AT, McCoy CP, Murad MH, et al. Association between industry affiliation and position on cardiovascular risk with rosiglitazone: cross sectional systematic review. BMJ 2010;340:c1344.
7. Hakoum MB, Jouni N, Abou-Jaoude EA, et al. Characteristics of funding of clinical trials: cross-sectional survey and proposed guidance. BMJ Open 2017;7:1-10.

8. Ahn R, Woodbridge A, Abraham A, et al. Financial ties of principal investigators and randomized controlled trial outcomes: cross sectional study. BMJ 2017;356:i6770.

9. Lundh A, Lexchin J, Mintzes B, et al. Industry sponsorship and research outcome. Cochrane Database Syst Rev 2017;2:MR000033.

10. McGauran N, Wieseler B, Kreis J, et al. Reporting bias in medical research - a narrative review. Trials 2010;11:37.

11. Page MJ, Boutron I, Hansen C, et al. Assessing risk of bias in studies that evaluate health care interventions: recommendations in the misinformation age. J Clin Epidemiol 2018;97:133-6.

12. Wiersma M, Kerridge I, Lipworth W. Dangers of neglecting non-financial conflicts of interest in health and medicine. J Med Ethics 2017:1-4.

13. International Committee of Medical Journal Editors. Recommendations for the conduct, reporting, editing and publication of scholarly work in medical journals. 2018. http://www.icmje.org/recommendations (Accessed 27 May 2019).

14. Licurse A, Barber E, Joffe S, et al. The impact of disclosing financial ties in research and clinical care: a systematic review. Arch Intern Med 2010;170:675-82.

15. Roseman M, Milette K, Bero LA, et al. Reporting of conflicts of interest in meta-analyses of trials of pharmacological treatments. JAMA 2011;305:1008-17.

16. Jørgensen L, Paludan-Müller AS, Laursen DR, et al. Evaluation of the Cochrane tool for assessing risk of bias in randomized clinical trials: overview of published comments and analysis of user practice in Cochrane and non-Cochrane reviews. Syst Rev 2016;5:80.

17. Boutron I, Page MJ, Higgins JPT, et al. Chapter 7: Considering bias and conflicts of interest among the included studies. Draft version (15 September 2018) for inclusion. In: Higgins JPT, Thomas J, Chandler J, eds. Cochrane Handbook for Systematic Reviews of Interventions. London: Cochrane. 